Article

\title{
Improved Delivery of Remedial Agents Using Surface Foam Spraying with Vertical Holes into Unsaturated Diesel-Contaminated Soil for Total Petroleum Hydrocarbon Removal
}

\author{
Rishikesh Bajagain (D), Prakash Gautam (D) and Seung-Woo Jeong *(D) \\ Department of Environmental Engineering, Kunsan National University, Gunsan 54150, Korea; \\ rbajagain@gmail.com (R.B.); prakash02gautam@gmail.com (P.G.) \\ * Correspondence: swjeong@kunsan.ac.kr; Tel.: +82-63-469-4767
}

Citation: Bajagain, R.; Gautam, P.; Jeong, S.-W. Improved Delivery of Remedial Agents Using Surface Foam Spraying with Vertical Holes into Unsaturated Diesel-Contaminated Soil for Total Petroleum Hydrocarbon Removal. Appl. Sci. 2021, 11, 781. https://doi.org/10.3390/app11020781

Received: 21 December 2020

Accepted: 12 January 2021

Published: 15 January 2021

Publisher's Note: MDPI stays neutral with regard to jurisdictional clai$\mathrm{ms}$ in published maps and institutional affiliations.

Copyright: (C) 2021 by the authors. Licensee MDPI, Basel, Switzerland. This article is an open access article distributed under the terms and conditions of the Creative Commons Attribution (CC BY) license (https:// creativecommons.org/licenses/by/ $4.0 /)$.
Featured Application: This study will be of interest to the readership as it works with increasingly popular biore-mediation and oxidation methods, offering a low-cost and green method for enhancing the ef-ficacy of both.

Abstract: Surface foam spraying technologies, employing natural infiltration processes, have recently been suggested to not disturb or mix contaminated soils. However, effective delivery of reactive remedial agents to the bottom area of a contaminated region using only natural infiltration processes can be a challenge. This study aimed to improve the delivery of remedial agents such as oxidants, microorganisms, and nutrients to all depths of $30 \mathrm{~cm}$ thick unsaturated diesel-contaminated soil using small vertical soil holes. Three vertical holes, occupying $0.8 \%$ of the total soil volume and $3 \%$ of the soil surface area, were made inside the $17.3 \mathrm{~kg}$ soil column. Persulfate oxidation foam and subsequent bioaugmentation foam spraying were applied for remediation of contaminated soil. Foam spraying with vertical soil holes improved the uniformity of distribution of remedial agents throughout the soil, as evidenced by the uniform $\mathrm{pH}$, higher volumetric soil water content, and a microbial population of $>10^{7} \mathrm{CFU} / \mathrm{g}$. Therefore, the total petroleum hydrocarbon (TPH) removal efficiency (88-90\%) from bottom soils was enhanced compared to soil columns without holes (72-73\%) and the control test (5-9\%). The kinetic study revealed that relatively similar TPH biodegradation rates $\left(0.054-0.057 \mathrm{~d}^{-1}\right)$ can be obtained for all soil depths by using this new and simple approach.

Keywords: diesel-contaminated soil; surfactant foam; infiltration; oxidation; biodegradation; TPH

\section{Introduction}

There are several cost-effective and green remediation processes (e.g., natural attenuation or bioremediation) for hydrocarbon-contaminated sites in current practice [1-3]. Although biological treatments are promising methods, they are tedious because the cycle times of bioremediation for total petroleum hydrocarbon (TPH) are relatively long and exhibit incomplete removal of hydrocarbons [4,5]. Furthermore, the remedial agents may suffer poor contact or poor infiltration in the soil [6], owing to which the degradation potential may be insufficient to meet soil-TPH regulatory limits throughout the soil. The remediation of contaminated soils in the unsaturated zone is challenging because the access of the remedial agents to the contaminants is limited by factors such as depth, water saturation, soil anisotropy and gravity in unsaturated soils [7].

Chemical oxidation is a more powerful means for remediation compared to the bioremediation method. However, its efficiency is often limited by low soil permeability, high reactivity of oxidants with soil components (e.g., natural organic matter), radical scavenging, and the difficulty in controlling the heat emitted from oxidation reactions, which 
could further affect biological forms in the soil [6,8-11]. For faster and enhanced remediation efficiency, current practice is to combine chemical oxidation with bioremediation treatment for the remediation of petroleum-contaminated soil [11-17]. Although chemical oxidation pretreatment is required for faster remediation of oil contaminants, good contact between contaminants and remedial agents is essential to achieve the remediation goals. The uniform delivery of chemical reactants to the unsaturated zone is a difficult task [18].

The inherent issues related to solution-based delivery to an unsaturated medium (e.g., preferential flow and contaminant mobilization) can be overcome by using foam to deliver the remedial agents [19]. Some methods for foam transport in vadose zone remediation using unsaturated narrow columns (with an internal diameter (i.d.) of 2.4 to $5 \mathrm{~cm}$ ) have been documented [18-20]. Surfactant foam can be applied for non-aqueous phase liquid (NAPL) flushing; thermal remediation; and nanoparticle, chemical, and nutrient delivery to enhance remediation of organic contaminants [19-22]. Furthermore, Srirattana et al. [22] demonstrated that surfactant foam was effective at carrying iron nanoparticles (NZVI) to enhance TCE volatilization in unsaturated sand-packed columns $(16 \mathrm{~cm}$ long, $2 \mathrm{~cm}$ i.d.). They suggested that there was a relative improvement in the delivery of reagents when pressurized foam was injected into porous media. Indeed, most studies of foam application to porous media have used pressure-driven injection.

Recently, surface foam spraying remediation technology using natural infiltration without soil mixing or disturbance has been suggested. As such, serial oxidation-bioaugmentation foam spraying has been tested in small scale reactors containing $5 \mathrm{~cm}$ thick unsaturated soil [23,24]. However, the delivery of remedial agents to unsaturated soil thicker than $5 \mathrm{~cm}$ using natural infiltration has been scarcely studied. In this study, we evaluated the natural infiltration of surfactant foam carrying reactive reagents through vertical holes in order to improve poor and uneven distribution of remedial agents throughout the soil. Furthermore, spreading reagents using foam and slowly introducing reagents into the soil are the main ideas of the study. The remediation reagents into the soil can be gradually introduced, as foam dissolves, but the instant release of liquid may result in preferential flows.

The first objective of this study is to evaluate the oxidation-bioaugmentation coupled system with unsaturated $30 \mathrm{~cm}$ thick soil to check the delivery limitations of reagents to the soil via gravity driven natural infiltration. The second objective of this study is to improve delivery of remedial agents to the soil using surfactant foam spraying with three vertical soil holes at triangular points. This is a column study using persulfate for oxidation pretreatment coupled with microbes and nutrients for bioaugmentation. Surfactant foam is used to carry the persulfate, nutrients, and microbes. The goal of this study is to achieve higher TPH biodegradation rates in the bottom area of the soil column. The results of this study will be helpful in field-scale soil remediation to achieve an enhanced contaminant removal from contaminated soil by simple gravity driven foam spraying technology that uses lower cost, materials, energy, and manpower.

\section{Materials and Methods}

\subsection{Soil Used for This Study}

This study used artificial soil made in the laboratory by mixing $80 \%$ fine sand (HiTech, Seoul, Korea), 10\% kaolin clay (Samchun, Pyeongtoek, Korea), and 10\% peat-moss (Lithuania). The important physicochemical properties of the experimental soil are summarized in Table S1 (supplementary data). The soil was then artificially contaminated with diesel-oil (SK-oil, Seoul, Korea) at $120 \mathrm{~mL}$ diesel per kg soil. Finally, the contaminated soil was left for weathering (stabilization of diesel in soil) and stabilized for 60 days. During weathering process, the contaminated soil was mixed with a small hand shovel once a week. After stabilization, the experimental soil was transferred into the soil columns.

\subsection{Preparation of Remediation Solutions}

Two types of remedial solutions were used in this study, an oxidant solution and a bioaugmentation solution. For the former, this study used sodium persulfate (Samchun) 
at a $50 \mathrm{mN}$ concentration for oxidation pretreatment as reported in literature [24], and it is also advantageous over other oxidants for higher infiltration [6]. The bioaugmentation solution was prepared by incubation of the TPH-degrading bacterial strain, Acinetobacter sp. K-6 in sterilized R2A (MB cell) broth for 12-15 h in a horizontal shaker at $21{ }^{\circ} \mathrm{C}$ and $150 \mathrm{rpm}$. This oil-degrading bacterium was isolated from the oil-contaminated soil; this has been identified, characterized, and investigated elsewhere [25]. Inorganic fertilizers, $\mathrm{NH}_{4} \mathrm{NO}_{3}$ (Samchun) and $\mathrm{KH}_{2} \mathrm{PO}_{4}$ (Daejung, Siheung, Korea), were added to the bacterial solution to maintain the C:N:P ratio of 100:10:1 [26]. For the control treatment, deionized water from a water purification system (Human Power Corporation, Seoul, Korea) was used.

\subsection{Oxidant and Bioaugmentation Foam Generation and Characterization}

The surfactant, sodium $\mathrm{C}_{14-16}$ alpha olefin sulfonate (AOS; AK Precision Chemical Co., Ltd., Daejeon, Korea), was used to generate the foam. In this study, two types of remedial foams were prepared, oxidant foam for the pretreatment of TPH by oxidation and bioaugmentation foam for the biodegradation of TPH. The oxidant foam was generated by injecting air at a flow rate of $800 \mathrm{cc} / \mathrm{min}$ through a capillary tube into the mixture of oxidant (50 $\mathrm{mN} \mathrm{Na}_{2} \mathrm{~S}_{2} \mathrm{O}_{8}$ ) and $0.1 \%$ AOS solution. In this study, persulfate oxidation ("PS") foam refers to sodium persulfate-surfactant foam. The bioaugmentation foam was generated by injecting air at the same flow rate into the mixture of bacterial solution inoculated in $\mathrm{R} 2 \mathrm{~A}, 0.1 \%$ AOS, and inorganic nutrients (1:1 ratio of bacterial solution with the AOS solution). It was found that the surfactant (AOS) did not show a negative impact on the population of bacteria (Acinetobacter sp K-6). An analysis using bacterial solution (prepared in $\mathrm{R}_{2} \mathrm{~A}$ medium) found that the colony forming units (CFU) were $6.1 \times 10^{9} \mathrm{CFU} / \mathrm{L}$ and $5.2 \times 10^{9} \mathrm{CFU} / \mathrm{L}$ before and after adding AOS, respectively.

We characterized the two foams using several techniques. Foam quality was identified as suggested in the literature $[19,27]$. The foam stability was determined in terms of half-life, defined as the time taken for the foam to decline to half the original aerated volume [28]. Foamability [29] was identified as the time taken to generate $1000 \mathrm{~mL}$ of surfactant foam inside a mass cylinder. From the half-life and foamability, we determined the performance of the foam in terms of the Foam Composite Index (FCI) [30]. The foam density was measured by pouring surfactant foam in an apparatus of known volume and measuring its weight [31]. Foam expansion ratio was identified as the ratio of liquid used to produce a certain volume of foam [32]. In this experiment, we produced $1000 \mathrm{~mL}$ of foam by which an expansion ratio was calculated. Finally, in situ generation of surfactant bubbles was captured using $0.001 \mathrm{~g}$ of brilliant blue dye that was added to $65 \mathrm{~mL}$ of the surfactant solution. The properties of the foam were not affected by the addition of the dye.

\subsection{Soil Column and Vertical Holes in the Soil Column}

The soil column experiment was conducted in a laboratory using oxidation foam conjugated with bioaugmentation serial foam spraying (column diameter, $25 \mathrm{~cm}$; height, $70 \mathrm{~cm}$, see Figure S1). The bottom of the soil columns had several holes for leachate discharge. A fine iron mesh was placed at the soil column bottom to prevent the soil loss. Of the diesel-contaminated soil, $17.3 \mathrm{~kg}$ was compressed into each tank, resulting in a soil thickness of $30 \mathrm{~cm}$ (soil volume $=14,726 \mathrm{~cm}^{3}$, bulk density $=1.175 \mathrm{~g} / \mathrm{mL}$ ).

Three small vertical holes $(2.5 \mathrm{~cm}$ diameter each) from surface to $25 \mathrm{~cm}$ depth were made in an equilateral triangular point (Figure 1) by using a soil core sampler (Eijkelkamp Agricultural Equipment, Giesbeek, The Netherlands). The vertical holes occupied $0.8 \%$ of the total soil volume and 3\% of the soil column surface area. Two soil-moisture sensors (Em50, Decagon Devices, Inc., WA, USA) were installed at depths of 15 and $25 \mathrm{~cm}$ (in the center of soil tanks). A total of 1.2 pore volume (PV) of oxidant-bioaugmentation solution was used in the soil column. Note that solution was loaded in foam. The oxidation foam was sprayed on day 1 (0.2 PV solution; $1.64 \mathrm{~L})$ and left for oxidation reaction for 2 days. Then, from day 3 , an equal volume of bioaugmentation foam was periodically sprayed every second day for 28 days (total 1 PV; 8.19 L). For the control tank, the same volume 
of deionized water was poured onto the soil surface. The soil columns were placed on metal shelves and containers were installed below them for leachate collection. All the experiments were conducted at ambient laboratory temperature $\left(21 \pm 1^{\circ} \mathrm{C}\right)$.

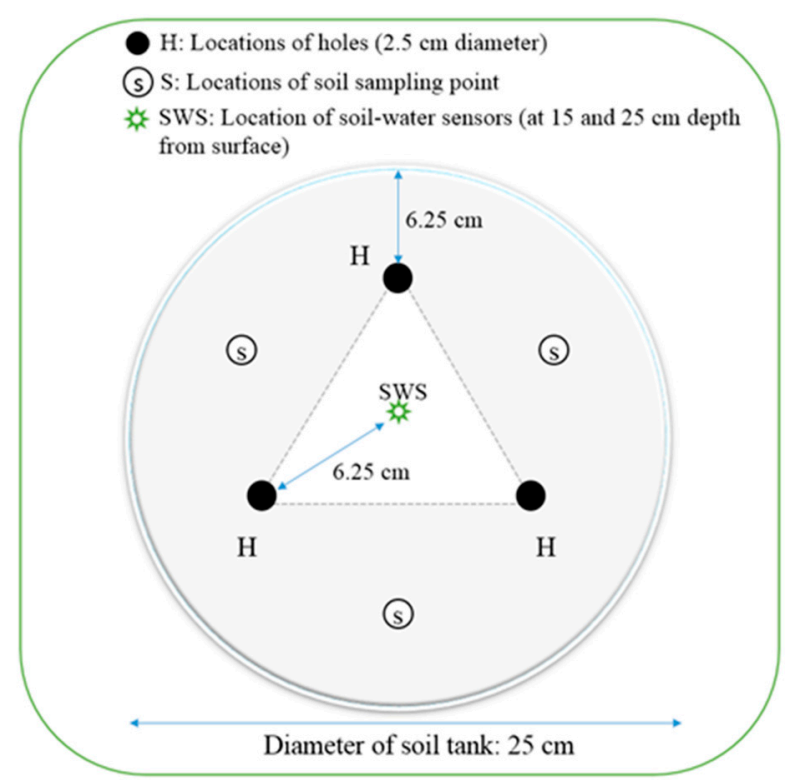

Figure 1. Schematic diagram of the top view of the soil tank indicating position of holes (only $3 \%$ of soil surface area) and soil sampling locations for total petroleum hydrocarbon (TPH) concentration and other parameters (70 cm long column containing $30 \mathrm{~cm}$ soil height).

\subsection{Sampling and Measurements}

Soil sampling was performed three times during the experiment to minimize soil disturbance: on the first day (initial conditions), third day (after oxidation), and 31st day (after biodegradation). Soil was sampled by using a graduated core sampler at depths of 5 , 15 and $25 \mathrm{~cm}$, and composite samples were prepared from each depth profile measuring $10 \mathrm{~g}$ for TPH extraction. After sampling, the holes created by the core sampler were re-filled with soil from the tanks. TPH analysis was performed by the Korean Soil Analysis Method, ES 07552.1a [28,33,34]. TPH was then extracted with dichloromethane (Samchun) by using a sonicator (Sonics Vibra Cell, CT, USA) and analyzed by GC-FID with a capillary column (Agilent, HP 6890, CA, USA) $[28,35]$. The hydrocarbons (n-alkanes) within the range $\mathrm{C}_{8}-$ $\mathrm{C}_{40}$ (i.e., n-octane to n-tetracontane) were quantified as TPHs [28] using an eight-point calibration curve obtained from the injection of standard TPH solution of n-alkanes (Florida TRPH Standard $500 \mu \mathrm{g} / \mathrm{mL}$, Restek, PA, USA).

The $\mathrm{pH}$ (soil: deionized water $=1: 5)$ and electric conductivity $(\mathrm{EC})$ were measured by using a pH meter (MultiMeter K5000-CP, NeoMet, iSTEK, Seoul, Korea). Similarly, the oxidation-reduction potential (ORP) of soil was measured using an ORP electrode (iSTEK). Gravimetric soil water content $(w / w)$ was determined by placing $10 \mathrm{~g}$ of soil samples in a drying oven (JEIO TECH, FO-600M) at $105^{\circ} \mathrm{C}$ for $24 \mathrm{~h}$ and water content was measured using a digital balance after drying [36]. The volumetric soil water content (VWC) was monitored for the experimental period by using soil-moisture sensors and recorded using software $\left(\mathrm{ECH}_{2} \mathrm{O}\right.$ Utility). Soil organic matter (SOM) was determined by the loss on ignition (LOI) method after oven drying at $105^{\circ} \mathrm{C}$ using a furnace (WiseTherm, Wisd.B). The leachate volume was measured by using a measuring cylinder the day after each foam spraying/solution pouring. The bacterial population (CFU/g of dry soil) was monitored throughout the experimental period by the dilution and plating method [24]. Briefly, a $1 \mathrm{~g}$ soil sample was serially diluted in water, and $100 \mu \mathrm{L}$ of each diluted soil suspensions was sprayed over the surface of solid agar in petri plates (Agar A + nutrient, $R_{2} A$ ). Then, the petri plates were incubated in an incubator at $28^{\circ} \mathrm{C}$ for $48-72 \mathrm{~h}$. All the measurements were performed in duplicate. 


\subsection{Statistical Analysis}

The data were entered into an Excel file (Microsoft Office Excel 2016) to calculate descriptive statistics (mean; standard deviation, SD; standard error, SE). These data were used in one-way ANOVA analysis, and the significant difference of the mean values of the various treatments at $p<0.05$ were determined through the Tukey (honestly significant difference) test using OriginPro 8.5 software.

\section{Results and Discussion}

\subsection{Volumetric Soil Water Content (VWC) during Soil Column Experiment}

This study monitored volumetric soil water content $\left(\mathrm{VWC}, \mathrm{m}^{3} / \mathrm{m}^{3}\right)$ over a one-month period ( 2 day oxidation and 28 day bioaugmentation). The liquid uptake in the sediment is an indicator of the amount of remedial agent delivered to the contaminated area [18]. Figure 2a depicts the change in soil water content at $25 \mathrm{~cm}$ soil depth during the oxidation period of 2 days $\left(48 \mathrm{~h}\right.$ ). During $\mathrm{Na}_{2} \mathrm{~S}_{2} \mathrm{O}_{8}$ foam spraying, the soil water content sharply increased up to maximum value (for the first five hours) which remained constant for $48 \mathrm{~h}$ of oxidation period. $\mathrm{Na}_{2} \mathrm{~S}_{2} \mathrm{O}_{8}$ can be transported to the bottom region twice as fast using vertical soil holes. The VWC in soil reached $0.171 \mathrm{~m}^{3} / \mathrm{m}^{3}$ when $\mathrm{Na}_{2} \mathrm{~S}_{2} \mathrm{O}_{8}$ was applied to the soil surface with holes, whereas without holes, the VWC only reached $0.094 \mathrm{~m}^{3} / \mathrm{m}^{3}$. Moreover, a greater value of VWC at $25 \mathrm{~cm}$ soil depth was recorded rather than at $15 \mathrm{~cm}$ soil depth (Supplementary Figure S2), implying a faster movement of remedial agents through holes. Initially, a slight increase in VWC from 0.027 to $0.032 \mathrm{~m}^{3} / \mathrm{m}^{3}$ was observed in the control soil column, though the change was negligible. The results show that the combination of surfactant foam use and holes plays an important role in the movement of remedial agents into the bottom region of unsaturated soil.

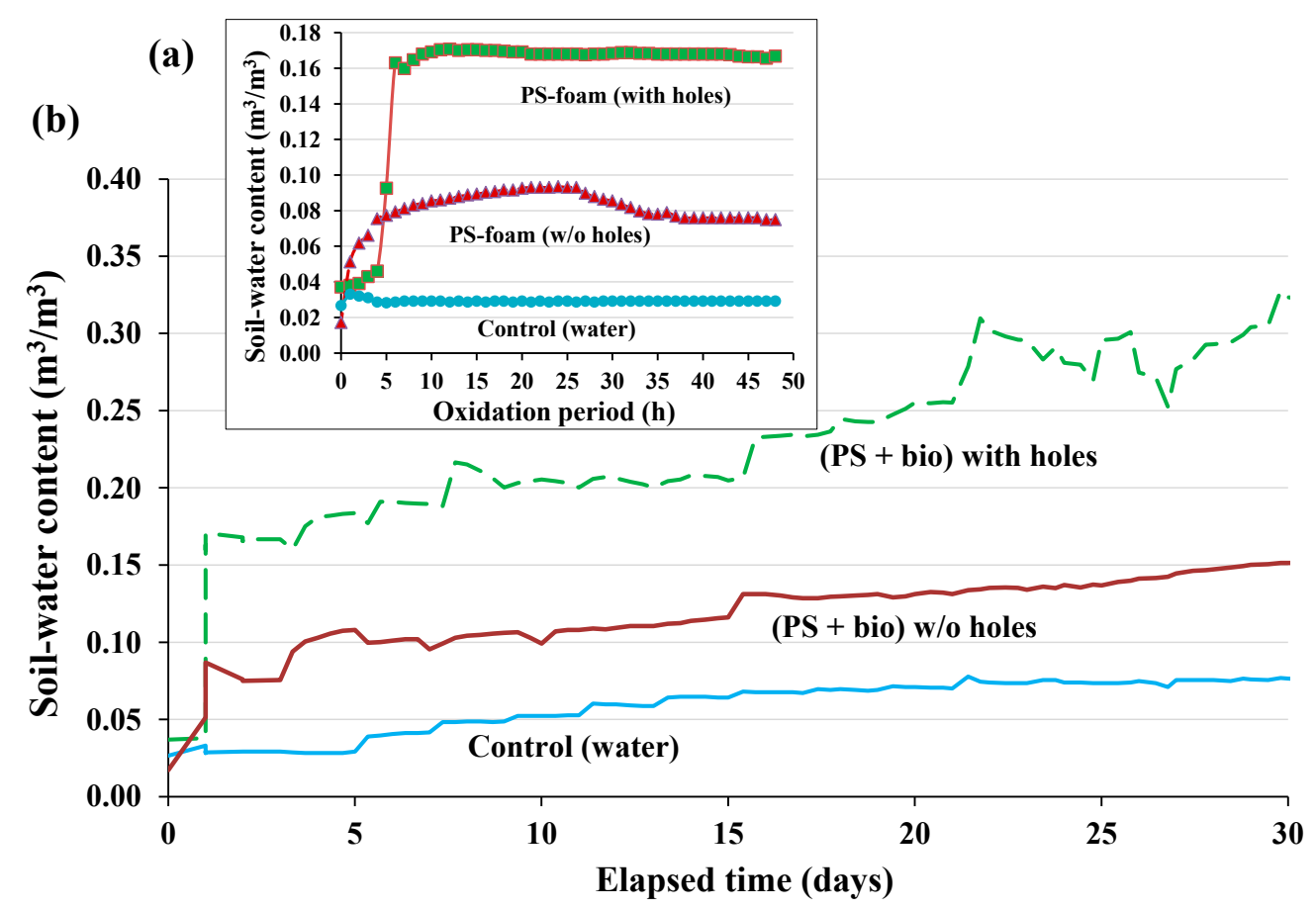

Figure 2. Change in volumetric water content (VWC) in soil columns with or without using vertical holes at $25 \mathrm{~cm}$ depth during (a) persulfate oxidation (PS) for two days, and (b) oxidation followed by bioaugmentation (PS + bio) for 28 days (4 weeks). Note that foam was sprayed onto the soil surface. Control indicates the treatment of water in soil columns with holes.

Figure $2 \mathrm{~b}$ shows the change in soil water content during the bioaugmentation 28 dayperiod. In this period, a 2-3-fold increase in VWC oxidation period was observed. The VWC in the soil column with vertical holes, $\mathrm{Na}_{2} \mathrm{~S}_{2} \mathrm{O}_{8}$ foam + bio foam (with holes), had a value 
of $0.322 \mathrm{~m}^{3} / \mathrm{m}^{3}$ at soil depth of $25 \mathrm{~cm}$; however, the VWC without holes, $\mathrm{Na}_{2} \mathrm{~S}_{2} \mathrm{O}_{8}$ foam + bio foam (w/o holes), reached only $0.151 \mathrm{~m}^{3} / \mathrm{m}^{3}$ holes. The results show that small vertical holes improved the distribution of remedial agents in soil, demonstrating a 2-3-fold increase in VWC. Enhanced delivery of remedial agents occurred in the bottom area of the soil column when using a combination of surface surfactant foam spray and vertical small holes.

In the control test using holes, "Water for control (with holes)" in Figure 2, the VWC reached a maximum value of $0.076 \mathrm{~m}^{3} / \mathrm{m}^{3}$, even though the same volume of water as the volume of surfactant solution (for foam) was poured onto the soil. The results imply that water may infiltrate only through preferential flow paths in the unsaturated soil, showing a low VWC at $25 \mathrm{~cm}$ soil depth [37,38]. Leachate collected from the bottom of the soil column (see Figure S3) clearly showed that the volumes thereof in "water for control (with holes)" were always higher than that in other conditions. These results imply that water infiltrated only through preferential flow paths in the unsaturated soil.

After being broken, surfactant foam may slowly change into a solution, allowing its gradual infiltration into the soil. This suggestion was supported by the visualization experiment shown in Figure S4. During this experiment, foam was poured into a plastic box of $22 \mathrm{~cm}$ long, $13 \mathrm{~cm}$ wide, and $7.5 \mathrm{~cm}$ tall; it had a $2.5 \mathrm{~cm}$ hole at the bottom that was connected to the neck $(2.5 \mathrm{~cm}$ i.d., similar to the soil holes used in this study) of a $1 \mathrm{~L}$ volumetric flask (see Figure S4). No foam movement through the neck was immediately observed after the foam was poured into the box. Only after it broke was $200 \mathrm{~mL}$ of liquid collected; this amount is equal to the volume of the injected liquid.

The results of foam characterization are summarized in Supplementary Text S1. Our generated foam was very light, expandable, dry, and hexagonal in shape (see Table S2 and Figure S5). It could not flow directly through the hole without pressure. After the foam broke and changed into a liquid, the liquid reagent was easily transported through the holes in the soil columns. This breaking led to a slow release of remediation reagents into the soil, preventing a fast flow along preferential flow paths. As shown in the volume of leachate collected from the bottom of soil column (see Figure S3), the release of remediation reagent using a foam spray (either with or without holes) produced lower leachate volumes than if a water pulse was used, even with holes. The lower leachate volume indicated that the remediation reagents released were more present in the contaminated soil.

\subsection{TPH Degradation in the Soil Column}

Monitored TPH concentrations during the experimental period are compiled in Figure 3. Residual TPH concentrations were averaged from the composite samples (soil mixed from all depths). After the 2 day application of $\mathrm{Na}_{2} \mathrm{~S}_{2} \mathrm{O}_{8}$ in soil containing holes, almost half (49.3\%) of the TPH was oxidized, while only $33.5 \% \mathrm{TPH}$ was oxidized in the soil without vertical holes. A greater TPH degradation in the soil column with vertical holes is attributed to higher soil water content during oxidation (Figure 2a, Supplementary Figure S2), resulting in a higher infiltration of the reagent (oxidant) into the soil. In addition, the ORP of soil (initially $310 \mathrm{mV}$ ) increased after oxidation. When AOS was added to $\mathrm{Na}_{2} \mathrm{~S}_{2} \mathrm{O}_{8}$, there was a slight decrease in ORP from 442 to $424 \mathrm{mV}$, showing that a retained capacity for oxidation after the addition of AOS could oxidize TPH in soil.

Figure 3 shows that an enhanced TPH removal when employing vertical holes was observed after bioaugmentation of persulfate treated soil. On day 30 after bioaugmentation, the residual soil-TPH concentration with holes decreased to $776 \mathrm{mg} \mathrm{kg}^{-1}$ showing $88.4 \%$ removal efficiency, suggesting that $39.1 \%$ of TPH was additionally removed through the biodegradation process. The overall TPH degradation efficiency was clearly higher than that without the holes by a 61\% removal efficiency (final TPH, $2494 \mathrm{mg} \mathrm{kg}^{-1}$, "(PS + Bio) w/o holes" in Figure 3). Our previous study found that the introduction of remedial agents using a foam spray resulted in higher infiltration and thereby enhanced TPH removal efficiency compared to the use of an aqueous solution of the same remedial agents [23]. Furthermore, in the control soil column ("Control (water)" in Figure 3), the 
average TPH concentration somewhat decreased and did not show a distinct change in TPH concentration, remaining above $6000 \mathrm{mg} \mathrm{kg}^{-1}$. The TPH fractional analysis by Bajagain et al. [24], which used the same oxidant and oil-degrading microbes, showed less biodegradation in the $\mathrm{F}_{2}$ section $\left(\mathrm{C}_{18}-\mathrm{C}_{22}\right)$ than in the $\mathrm{F}_{1}$ section $\left(\mathrm{C}_{8}-\mathrm{C}_{16}\right)$. Pretreating persulfate significantly increased the biodegradation rate of $19 \%$ for the $\mathrm{F}_{2}$ section of TPH.

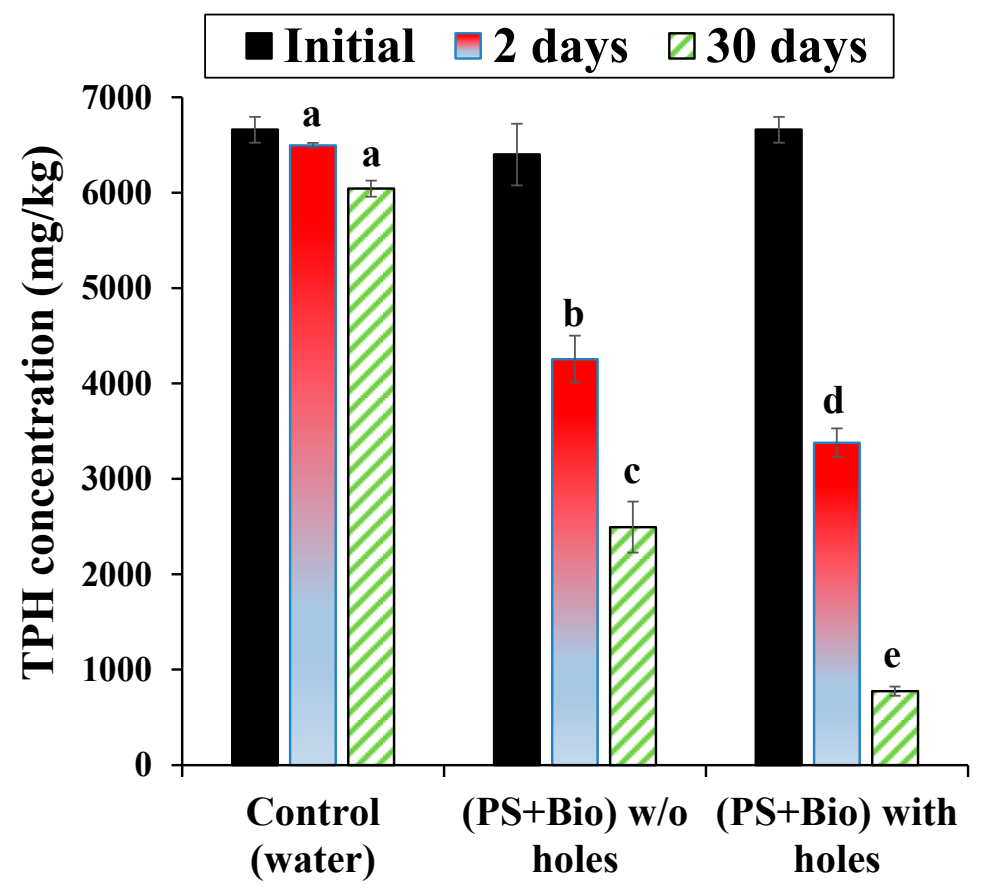

Figure 3. Effect of vertical soil holes on TPH removal by surfactant foam spraying. "Control (water)" indicates that water was poured onto the soil surface. "(PS + Bio) w/o holes" indicates persulfate (PS) oxidation (2 days) followed by bioaugmenation (Bio) (30 days) in the soil column without holes. "(PS + Bio $) \mathrm{w} /$ holes" indicates those with holes. The TPH was extracted from composite samples by mixing soils from three depths. The different letters (a-e) above the bars indicate significant differences ( $p<0.05$, Tukey's test).

\subsection{Vertical TPH Removal at Three Depths in Soil Column}

Soil samples were taken at three depths $(5,15$, and $25 \mathrm{~cm})$ to verify the vertical TPH remediation efficiency of chemical oxidation and biodegradation. Figure 4 shows residual TPH concentrations in soil columns vertically at the three tested depths. TPH concentrations at $25 \mathrm{~cm}$ depth always showed higher values than those at the shallower depths. The results also demonstrated a difference in TPH removal efficiency between with holes and without holes. In the soil column with holes, the residual TPH concentrations decreased to 3125 (5 cm depth), 3143 (15 cm depth), and $3742 \mathrm{mg} \mathrm{kg}^{-1}$ (25 cm depth) by using only $0.2 \mathrm{PV}$ of $\mathrm{Na}_{2} \mathrm{~S}_{2} \mathrm{O}_{8}(1.64 \mathrm{~L})$ in the first 2 days of the oxidation period with corresponding TPH removal efficiencies of 43.8, 52.8, and $53.1 \%$ at the respective depths of 5,15 , and $25 \mathrm{~cm}$. In the soil column without holes, soil-TPH was reduced to 4296,4785 , and $4807 \mathrm{mg} \mathrm{kg}^{-1}$ from the respective depths of 5, 15, and $25 \mathrm{~cm}$ with corresponding efficiencies of 24.9, 25.2, and $32.9 \%$. In the control, there was no distinct breakthrough at 2 days with the residual $\mathrm{TPH}$ in the range $6427-6545 \mathrm{mg} \mathrm{kg}^{-1}$. 


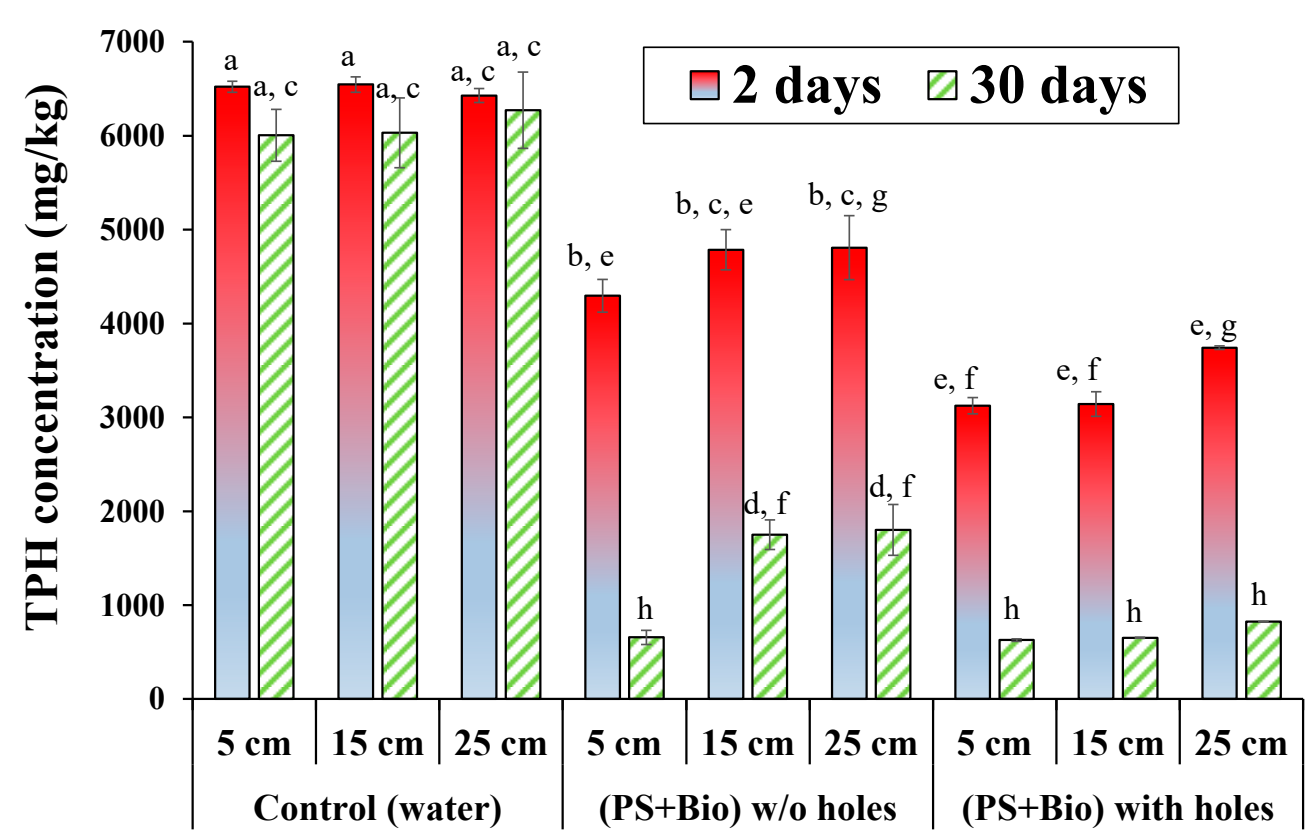

Figure 4. Residual TPH concentrations at three depths after PS oxidation (2 days) followed by biodegradation (Bio) (30 days). The different letters $(\mathbf{a}-\mathbf{h})$ above the bars indicate significant differences $(p<0.05$, Tukey's test).

After 30 days, the TPH concentrations in the soil column with holes fell to 628, 653, and $825 \mathrm{mg} \mathrm{kg}^{-1}$ at the respective depths of 5,15 , and $25 \mathrm{~cm}$ with corresponding TPH removal efficiencies of $90.6,90.2$, and $87.6 \%$. The additional $37-44 \%$ removal of TPH from the 2 day results was attributed to the biodegradation process. The residual soil-TPH values in the column without holes were 658,1750 , and $1800 \mathrm{mg} \mathrm{kg}^{-1}$, with removal efficiencies of 89.7, 72.7 , and $71.9 \%$ from the corresponding depths of 5, 15, and $25 \mathrm{~cm}$. Although the TPH degradation for $5 \mathrm{~cm}$ region was similar in both cases, the difference in TPH degradation between soil regions at depths of 15 and $25 \mathrm{~cm}$ was higher. These results were as expected by the VWC measurements at $25 \mathrm{~cm}$, as shown in Figure 2. The VWC in the column with holes was twice as high as without holes, implying that the aqueous phase remediation agents were better delivered at the $25 \mathrm{~cm}$ depth.

Biodegradation generally relies on the ability of aqueous solutions containing amendments to infiltrate into contaminated areas. Therefore, the success of aqueous-supplied amendments is limited on the infiltration capacity and persistency since the electron acceptor or nutrient is often metabolized before it reaches the contaminated area [39]. The surfactant AOS used in the remedial agents not only enhanced the infiltration of remedial agents but also accelerated the dissolution of oil from soil which assisted biodegradation of soil-TPH [28,40]. However, Jeong et al. [28] reported that surfactant AOS did not result in any significant reduction in TPH concentration during 33 days of foam spraying, although there was a small variation during the initial 3-6 days of the observation period. Moreover, no significant contaminant movement occurred by surfactant foam flow; therefore, contaminants stay in foam-occupied regions and react with reactants $[18,20]$.

The result of the vertical soil-TPH change during experiment implies that it would be difficult to remove TPH present in a region deeper than those tested using remediation methods depending on natural-gravity-driven infiltration. The remediation of contaminated soils in unsaturated zones is challenging due to low access of remedial agents to contaminants, which is often limited by depth, soil anisotropy, and gravity in unsaturated soils [7]. The results of this study suggest that the coupling of oxidation and bioaugmentation foam spraying through vertical holes can be used for enhanced removal of TPH from various depths. Notably, these vertical holes comprise only $0.8 \%$ of the total soil volume and $3 \%$ of the soil surface in the column. 
There are several limitations in interpreting the results of this study, which evaluated the role of soil holes in the delivery of remediation agents to a $30 \mathrm{~cm}$ deep soil. An evaluation should be conducted on a larger scale to increase reliability of the hole impacts when foam spray is used. The delivery processes for liquid transport through holes after the foam breaks should be made clearer and explained in more detail. Making some soil holes would also enhance delivery of oxygen into the deeper area and might accelerate biodegradation. Finally, more removal mechanisms to use between pre-oxidation and biodegradation should be studied further.

\subsection{Vertical Biodegradation Kinetics of TPH in a Soil Column}

The biodegradation of TPH in contaminated soil is assumed to follow the firstorder degradation kinetics. The first-order degradation rates for the treatments in this study are shown in Figure 5. Note that the biodegradation rates were calculated from the TPH removal results to reflect only biodegradation after the oxidation pretreatment was completed.

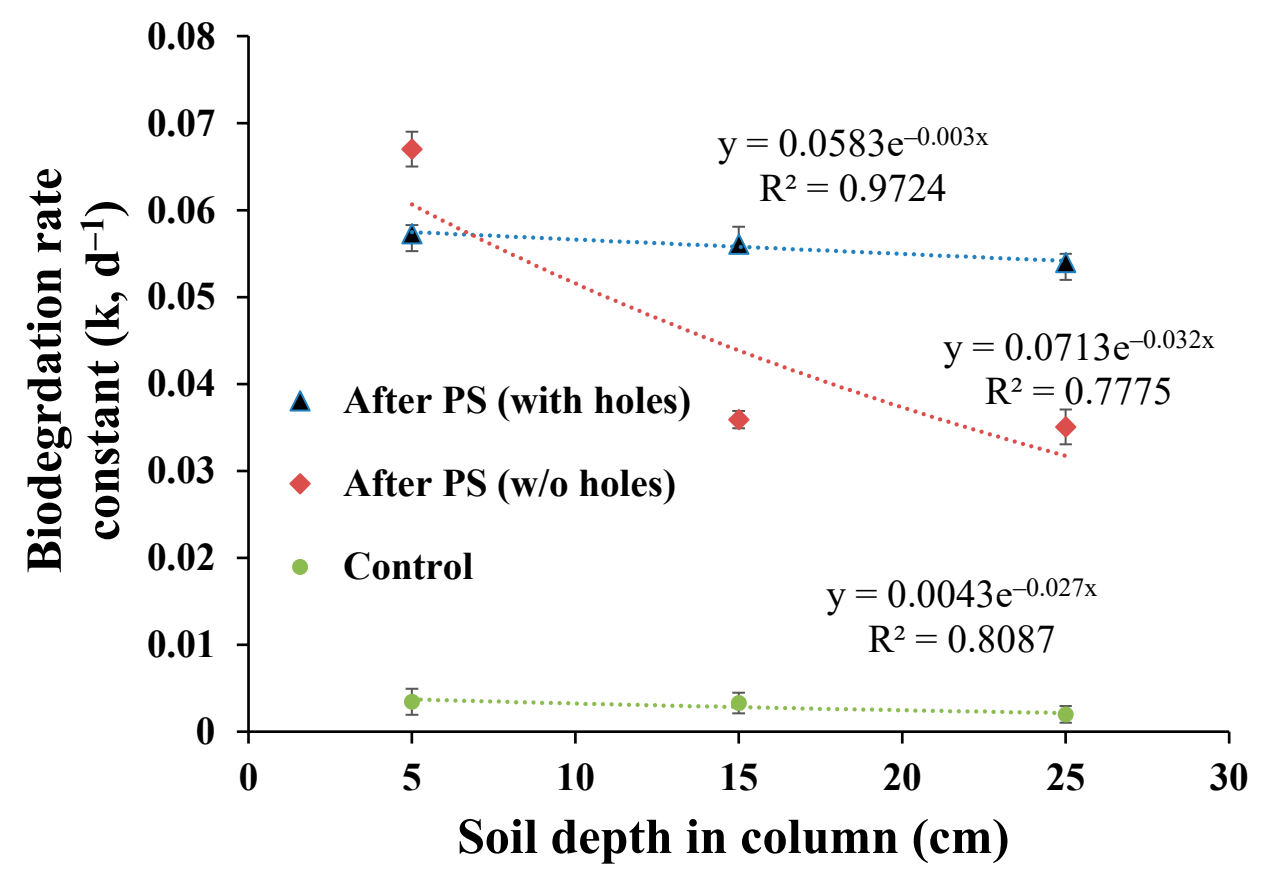

Figure 5. Comparison of the first order biodegradation rates $\left(k, \mathrm{~d}^{-1}\right)$ as a function of soil depth.

In the soil column without holes, the biodegradation rate constant was found to be $0.0670 \mathrm{~d}^{-1}$ at $5 \mathrm{~cm}$ soil depth, whereas the rate constants at 15 and $25 \mathrm{~cm}$ depths were 0.0359 and $0.0350 \mathrm{~d}^{-1}$, respectively. The vertical TPH biodegradation rates were distinct in that the rates at the two lowest depths were almost half the rate of the $5 \mathrm{~cm}$ depth. In contrast, similar TPH decay rates of $0.0573,0.0561$, and $0.0540 \mathrm{~d}^{-1}$ at 5,15 , and $25 \mathrm{~cm}$, respectively, were achieved in the column with vertical holes. The biodegradation rates for deeper soils (column with holes) were significantly higher than for the column without holes. These results showed that the TPH biodegradation rate was improved for deeper soil areas by using vertical holes with surfactant foam spray application. The TPH decay rate constants in control treatment (for 3-30 days) were found to be negligible with rate constants ranging from 0.0009 to $0.0030 \mathrm{~d}^{-1}$.

The higher biodegradation rates are attributed to the enhancement of bioavailability and biodegradability [28,41-44]. Thus, a one-time foam-sprayed oxidation pretreatment in conjunction with vertical holes may enhance bioavailability and biodegradability, accelerating the bioremediation of TPH contaminated soil at various depths in unsaturated conditions. 


\subsection{Changes in Microbial Population}

Results of the vertical change in microbial population after oxidation and biodegradation at various depths are presented (Figure 6, Supplementary Table S3). In general, the soil microbial population (CFU/g) decreased by one order of magnitude with soil $\mathrm{pH}$ decreasing after chemical oxidation (Table S4). This deleterious effect was minimal in the case of persulfate oxidation as the concentration of sodium persulfate $(50 \mathrm{mN})$ used was low. With the reclamation of $\mathrm{pH}$ after applying bioaugmentation foam, an exponential increase in CFU by 4 to 5 orders was observed. Moreover, the variation in the number of microorganisms as a function of depth in the column without holes was more significant compared to the column with holes.

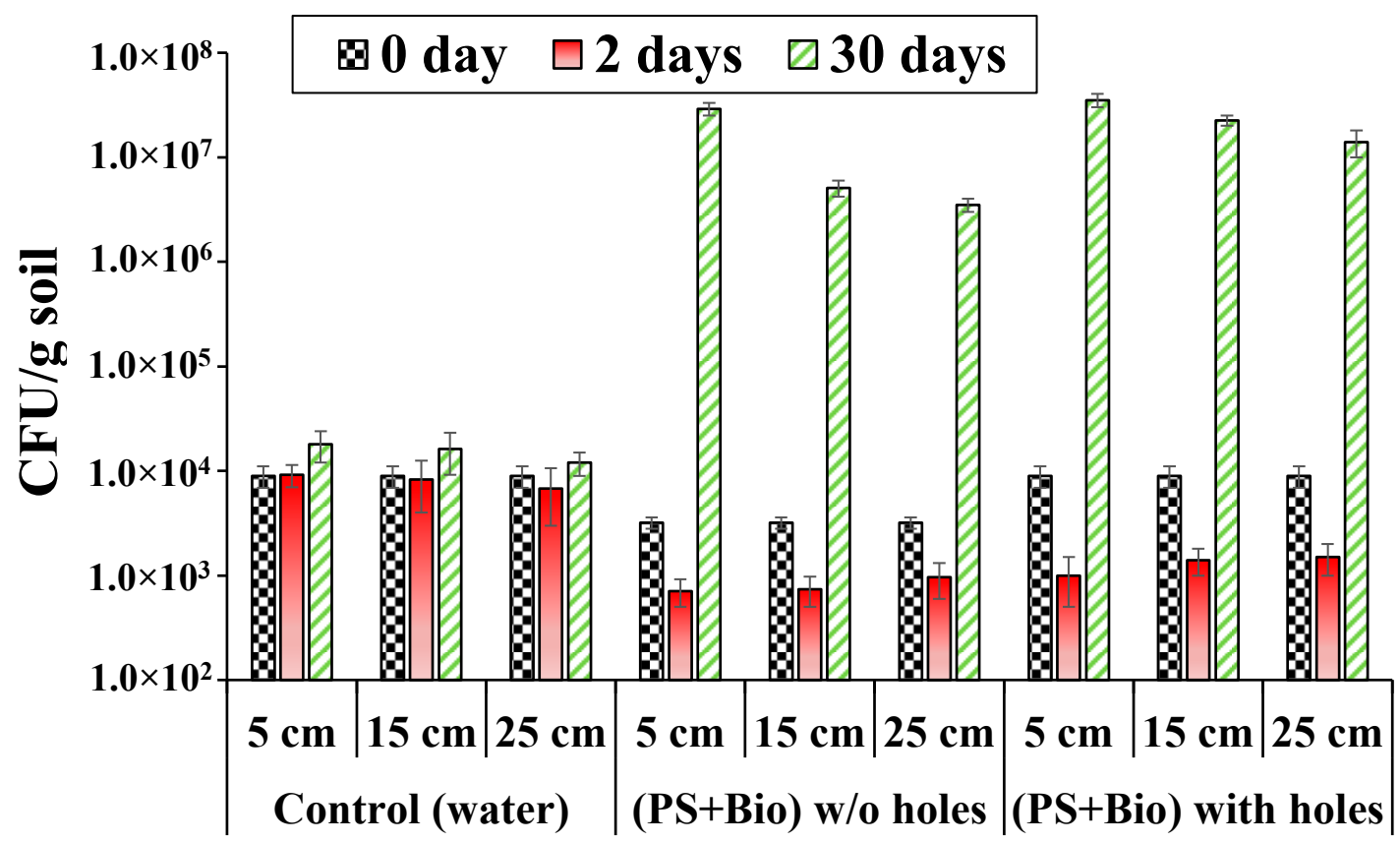

Figure 6. Change in soil microorganisms in three different soil depths $(5,15$, and $25 \mathrm{~cm}$ from the surface) during persulfate oxidation and bioremediation of TPH.

High CFU counts after 4 weeks indicated that the supplemented microorganisms had multiplied and reduced the total petroleum hydrocarbons through biodegradation. The results demonstrate that the TPH degradation is often related to the total microbial population which, in turn, is correlated to the $\mathrm{pH}$ of the soil. At day 30 , the microbial growth reached $10^{7}$ (maximum at $5 \mathrm{~cm}$ depth) CFU/g soil, while the TPH was significantly reduced. The CFU counts in deeper soils were slightly lower than shallower soils because of the lower $\mathrm{pH}$, insufficient nutrients, and lower oxygen levels at lower depths. The overall results of this study also suggest that the coupling of foam spray and vertical holes accelerated distribution of added microorganisms throughout diesel-contaminated soil.

\section{Conclusions}

A $30 \mathrm{~cm}$ soil column study was performed with and without vertical holes (occupying $0.8 \%$ of the soil volume and $3 \%$ of total surface area), and corresponding TPH removal efficiencies were evaluated at three depths $(5,15$, and $25 \mathrm{~cm})$. As compared to the column without holes, the vertical holes improved the water content in the soil columns suggesting better transport and distribution of remedial agents throughout the soil. As such, an enhanced TPH degradation result was obtained from lower depths in the soil column having vertical holes, achieving a TPH degradation efficiency of $88-90 \%$. In contrast, only $71-72 \%$ of TPH was removed from the lowest depth in the column without vertical holes.

An exponential increase in bacterial population (CFU) with a similar number $\left(10^{7} \mathrm{CFU} / \mathrm{g}\right.$ soil) in all soil depths was observed after treatments through holes. The results 
demonstrated that application through vertical hole oxidation followed by bioaugmentation is an effective method to increase the following: evenly distributed reactive reagents throughout the soil, maintenance of soil $\mathrm{pH}$ condition, and exponential bacterial growth. The results show the possibility of a simple natural delivery method of remediation agents to the unsaturated contaminated soil.

Supplementary Materials: The following are available online at https://www.mdpi.com/2076-3 417/11/2/781/s1, Figure S1: Foam sprayed soil columns. Figure S2: Change in volumetric water content (VWC) in soil columns using vertical holes during (a) persulfate oxidation (PS) for two days, and (b) oxidation followed by bioaugmentation (PS + bio) for 4 weeks. Note that the VWC was continuously monitored during experimental period (one month). Figure S3: Volume of leachate collected from the bottom of soil column as a function of time. Figure S4: Simple laboratory set-up to identify whether foam was propagated through the holes or remedial agent after the foam broken. Figure S5: Surfactant foam bubbles at different nodal angles and plateau border lengths for (a) pure AOS, (b) pre-oxidation, and (c) bio-augmentation. Table S1: Physicochemical properties of experimental soil. Table S2: Properties of the different surfactant foams applied in this study. Table S3: Change in microbial population (CFU/g) of soil during remediation. Table S4: Change in $\mathrm{pH}$ of soil during remediation. Text S1: Foam characterization.

Author Contributions: Conceptualization, R.B. and S.-W.J.; methodology, R.B. and P.G.; validation, R.B., P.G., and S.-W.J.; writing-original draft preparation, R.B. and P.G.; writing-review and editing, S.-W.J. All authors have read and agreed to the published version of the manuscript.

Funding: This work was supported by the National Research Foundation of Korea (2018R1A2B6006139).

Data Availability Statement: Not applicable.

Conflicts of Interest: The authors declare no conflict of interests.

\section{References}

1. Jeong, S.-W. Estimation of remediation cost for reducing cancer and non-cancer risk of a fuel-contaminated site. J. Korean Soc. Environ. Eng. 2019, 41, 286-291. [CrossRef]

2. Hadley, P.W.; Harclerode, M. Green remediation or sustainable remediation: Moving from dialogue to common practice. Remediat. J. 2015, 25, 95-115. [CrossRef]

3. Mohan, S.V.; Kisa, T.; Ohkuma, T.; Kanaly, R.A.; Shimizu, Y. Bioremediation technologies for treatment of PAH-contaminated soil and strategies to enhance process efficiency. Rev. Environ. Sci. Biotechnol. 2006, 5, 347-374. [CrossRef]

4. Chen, Y.; Lin, J.; Chen, Z. Remediation of water contaminated with diesel oil using a coupled process: Biological degradation followed by heterogeneous Fenton-like oxidation. Chemosphere 2017, 183, 286-293. [CrossRef]

5. Sirtori, C.; Zapata, A.; Oller, I.; Gernjak, W.; Agüera, A.; Malato, S. Decontamination industrial pharmaceutical wastewater by combining solar photo-Fenton and biological treatment. Water Res. 2009, 43, 661-668. [CrossRef]

6. Gautam, P.; Bajagain, R.; Jeong, S.-W. Soil infiltration capacity of chemical oxidants used for risk reduction of soil contamination. Ecotoxicol. Environ. Saf. 2019, 183, 109548. [CrossRef]

7. Reddy, K.R. Technical challenges to in-situ remediation of polluted sites. Geotech. Geol. Eng. 2010, 28, 211-221. [CrossRef]

8. Goi, A.; Trapido, M.; Kulik, N. Contaminated soil remediation with hydrogen peroxide oxidation. World Acad. Sci. Eng. Technol. 2009, 52, 185-189.

9. Lim, M.W.; Von Lau, E.; Poh, P.E. A comprehensive guide of remediation technologies for oil contaminated soil—Present works and future directions. Mar. Pollut. Bull. 2016, 109, 14-45. [CrossRef] [PubMed]

10. Kakosová, E.; Hrabák, P.; Černík, M.; Novotný, V.; Czinnerová, M.; Trögl, J.; Popelka, J.; Kuráň, P.; Zoubková, L.; Vrtoch, L'. Effect of various chemical oxidation agents on soil microbial communities. Chem. Eng. J. 2017, 314, 257-265. [CrossRef]

11. Polli, F.; Zingaretti, D.; Crognale, S.; Pesciaroli, L.; D'Annibale, A.; Petruccioli, M.; Baciocchi, R. Impact of the Fenton-like treatment on the microbial community of a diesel-contaminated soil. Chemosphere 2018, 191, 580-588. [CrossRef] [PubMed]

12. Goi, A.; Kulik, N.; Trapido, M. Combined chemical and biological treatment of oil contaminated soil. Chemosphere 2006, 63, 1754-1763. [CrossRef] [PubMed]

13. Gong, X.B. Remediation of weathered petroleum oil-contaminated soil using a combination of biostimulation and modified Fenton oxidation. Int. Biodeterior. Biodegrad. 2012, 70, 89-95. [CrossRef]

14. Kim, I.; Lee, M. Pilot scale feasibility study for in-situ chemical oxidation using $\mathrm{H} 2 \mathrm{O} 2$ solution conjugated with biodegradation to remediate a diesel contaminated site. J. Hazard. Mater. 2012, 241-242, 173-181. [CrossRef]

15. Lu, M.; Zhang, Z.; Qiao, W.; Wei, X.; Guan, Y.; Ma, Q.; Guan, Y. Remediation of petroleum-contaminated soil after composting by sequential treatment with Fenton-like oxidation and biodegradation. Bioresour. Technol. 2010, 101, 2106-2113. [CrossRef] 
16. Silva-Castro, G.A.; Rodelas, B.; Perucha, C.; Laguna, J.; González-López, J.; Calvo, C. Bioremediation of diesel-polluted soil using biostimulation as post-treatment after oxidation with Fenton-like reagents: Assays in a pilot plant. Sci. Total Environ. 2013, 445-446, 347-355. [CrossRef]

17. Sutton, N.B.; Grotenhuis, T.; Rijnaarts, H.H.M. Impact of organic carbon and nutrients mobilized during chemical oxidation on subsequent bioremediation of a diesel-contaminated soil. Chemosphere 2014, 97, 64-70. [CrossRef]

18. Zhong, L.; Szecsody, J.E.; Zhang, F.; Mattigod, S.V. Foam delivery of amendments for vadose zone remediation: Propagation performance in unsaturated sediments. Vadose Zone J. 2010, 9, 757-767. [CrossRef]

19. Shen, X.; Zhao, L.; Ding, Y.; Liu, B.; Zeng, H.; Zhong, L.; Li, X. Foam, a promising vehicle to deliver nanoparticles for vadose zone remediation. J. Hazard. Mater. 2011, 186, 1773-1780. [CrossRef]

20. Zhong, L.; Qafoku, N.P.; Szecsody, J.E.; Dresel, P.E.; Zhang, Z.F. Foam delivery of calcium polysulfide to the vadose zone for chromium (VI) immobilization: A laboratory evaluation. Vadose Zone J. 2009, 8, 976-985. [CrossRef]

21. Jeong, S.W.; Corapcioglu, M.Y.; Roosevelt, S.E. Micromodel study of surfactant foam remediation of residual trichloroethylene. Environ. Sci. Technol. 2000, 34, 3456-3461. [CrossRef]

22. Srirattana, S.; Piaowan, K.; Lowry, G.V.; Phenrat, T. Electromagnetic induction of foam-based nanoscale zerovalent iron (NZVI) particles to thermally enhance non-aqueous phase liquid (NAPL) volatilization in unsaturated porous media: Proof of concept. Chemosphere 2017, 183, 323-331. [CrossRef] [PubMed]

23. Bajagain, R.; Park, Y.; Jeong, S.W. Feasibility of oxidation-biodegradation serial foam spraying for total petroleum hydrocarbon removal without soil disturbance. Sci. Total Environ. 2018, 626, 1236-1242. [CrossRef] [PubMed]

24. Bajagain, R.; Lee, S.; Jeong, S.-W. Application of persulfate-oxidation foam spraying as a bioremediation pretreatment for diesel oil-contaminated soil. Chemosphere 2018, 207, 565-572. [CrossRef] [PubMed]

25. Chaudhary, D.K.; Bajagain, R.; Jeong, S.-W.; Kim, J. Biodegradation of diesel oil and n-alkanes (C18, C20, and C22) by a novel strain Acinetobacter sp. K-6 in unsaturated soil. Environ. Eng. Res. 2020, 25, 290-298. [CrossRef]

26. Bajagain, R.; Gautam, P.; Jeong, S.-W. Biodegradation and post-oxidation of fuel-weathered field soil. Sci. Total Environ. 2020, 734, 139452. [CrossRef]

27. Mulligan, C.N.; Eftekhari, F. Remediation with surfactant foam of PCP-contaminated soil. Eng. Geol. 2003, 70, 269-279. [CrossRef]

28. Jeong, S.W.; Jeong, J.; Kim, J. Simple surface foam application enhances bioremediation of oil-contaminated soil in cold conditions. J. Hazard. Mater. 2015, 286, 164-170. [CrossRef]

29. Longpré-Girard, M.; Martel, R.; Robert, T.; Lefebvre, R.; Lauzon, J.M.; Thomson, N. Surfactant foam selection for enhanced light non-aqueous phase liquids (LNAPL) recovery in contaminated aquifers. Transp. Porous Media 2020, 131, 65-84. [CrossRef]

30. Jing, J.; Sun, J.; Zhang, M.; Wang, C.; Xiong, X.; Hu, K. Preparation and rheological properties of a stable aqueous foam system. RSC Adv. 2017, 7, 39258-39269. [CrossRef]

31. Ranjani, I.S.; Ramamurthy, K. Relative assessment of density and stability of foam produced with four synthetic surfactants. Mater. Struct. 2010, 43, 1317-1325. [CrossRef]

32. Wang, H.; Guo, W.; Zheng, C.; Wang, D.; Zhan, H. Effect of temperature on foaming ability and foam stability of typical surfactants used for foaming agent. J. Surfactants Deterg. 2017, 20, 615-622. [CrossRef]

33. NIER. Korean Soil Analysis Methods; National Institute of Environmental Research: Incheon, Korea, 2013.

34. Taki, G.; Islam, M.N.; Park, S.J.; Park, J.H. Optimization of operating parameters to remove and recover crude oil from contaminated soil using subcritical water extraction process. Environ. Eng. Res. 2018, 23, 175-180. [CrossRef]

35. Bajagain, R.; Gautam, P.; Jeong, S.-W. Degradation of petroleum hydrocarbons in unsaturated soil and effects on subsequent biodegradation by potassium permanganate. Environ. Geochem. Health 2019, 42, 1705-1714. [CrossRef]

36. Gautam, P.; Bajagain, R.; Jeong, S.-W. Combined effects of soil particle size with washing time and soil-to-water ratio on removal of total petroleum hydrocarbon from fuel contaminated soil. Chemosphere 2020, 250, 126206. [CrossRef]

37. Nimmo, J.R. Preferential flow occurs in unsaturated conditions. Hydrol. Process. 2012, 26, 786-789. [CrossRef]

38. Jarvis, N.; Koestel, J.; Larsbo, M. Understanding preferential flow in the vadose zone: Recent advances and future prospects. Vadose Zone J. 2016, 15, 1-11. [CrossRef]

39. USEPA. Engineering Forum Issue: Considerations in Deciding to Treat Contaminated Unsaturated Soils In Situ; EPA/540/S-94/500; Office of Research and Development: Washington, DC, USA, 1993.

40. Zhu, H.; Aitken, M.D. Surfactant-enhanced desorption and biodegradation of polycyclic aromatic hydrocarbons in contaminated soil. Environ. Sci. Technol. 2010, 44, 7260-7265. [CrossRef]

41. Chemlal, R.; Abdi, N.; Lounici, H.; Drouiche, N.; Pauss, A.; Mameri, N. Modeling and qualitative study of diesel biodegradation using biopile process in sandy soil. Int. Biodeterior. Biodegrad. 2013, 78, 43-48. [CrossRef]

42. Suja, F.; Rahim, F.; Taha, M.R.; Hambali, N.; Rizal Razali, M.; Khalid, A.; Hamzah, A. Effects of local microbial bioaugmentation and biostimulation on the bioremediation of total petroleum hydrocarbons (TPH) in crude oil contaminated soil based on laboratory and field observations. Int. Biodeterior. Biodegrad. 2014, 90, 115-122. [CrossRef]

43. Vincent, A.O.; Felix, E.; Ize-Iyamu, O.K.; Daniel, E.E. Microbial degradation and its kinetics on crude oil polluted soil. Res. J. Chem. Sci. 2011, 1, 8-14.

44. Yudono, B.; Said, M.; Sabaruddin, K.; Napoleon, A.; Fanani, Z. Kinetics approach of biodegradation of petroleum contaminated soil by using indigenous isolated bacteria. J. Trop. Soils 2013, 16, 33-38. [CrossRef] 